Ling Li*, Elia Vecellio, Stephanie Gay, Rebecca Lake, Mark Mackay, Leslie Burnett, Douglas Chesher, Stephen Braye, Tony Badrick, Johanna I. Westbrook and Andrew Georgiou

\title{
Making sense of a haemolysis monitoring and reporting system: a nationwide longitudinal multimethod study of 68 Australian laboratory participant organisations
}

https://doi.org/10.1515/cclm-2017-0056

Received January 19, 2017; accepted August 9, 2017; previously published online September 15, 2017

\begin{abstract}
Background: The key incident monitoring and management systems (KIMMS) quality assurance program monitors incidents in the pre- and postanalytical phases of testing in medical laboratories. Haemolysed specimens have been found to be the most frequent preanalytical error and have major implications for patient care. The aims of this study were to assess the suitability of KIMMS for quality reporting of haemolysis and to devise a meaningful method for reporting and monitoring haemolysis.

Methods: A structured survey of 68 Australian KIMMS laboratory participant organisations was undertaken. Quarterly haemolysis reports (2011-2014) were analysed.

Results: Among 110 million accessions reported, haemolysis rates varied according to the reporting methods that participants used for assigning accessions ( $16 \%$ of participants reported haemolysis by specimen and $83 \%$ reported
\end{abstract}

*Corresponding author: Ling Li, Senior Research Fellow, Centre for Health Systems and Safety Research, Australian Institute of Health Innovation, Macquarie University, Level 6, 75 Talavera Road, North Ryde, Sydney, NSW 2109, Australia, Phone: +61 29850 2423, E-mail: ling.li@mq.edu.au

Elia Vecellio: Centre for Health Systems and Safety Research, Australian Institute of Health Innovation, Macquarie University, Sydney, NSW, Australia; and South Eastern Area Laboratory Services, NSW Health Pathology, Sydney, NSW, Australia

Stephanie Gay, Mark Mackay and Tony Badrick: Royal College of Pathologists Australasia Quality Assurance Programs, St. Leonards, NSW, Australia

Rebecca Lake, Johanna I. Westbrook and Andrew Georgiou: Centre for Health Systems and Safety Research, Australian Institute of Health Innovation, Macquarie University, Sydney, NSW, Australia Leslie Burnett: Genome.One, Garvan Institute of Medical Research, Darlinghurst, NSW, Australia; and Northern Clinical School, Sydney Medical School, University of Sydney, NSW, Australia

Douglas Chesher: Northern Clinical School, Sydney Medical School, University of Sydney, NSW, Australia; and Pathology North, NSW Health Pathology, Royal North Shore Hospital, St. Leonards, NSW, Australia Stephen Braye: Pathology North, NSW Health Pathology, Royal North Shore Hospital, St. Leonards, NSW, Australia; and Pathology North, NSW Health Pathology, Newcastle, NSW, Australia by episode) and counting haemolysis rejections (61\% by specimen, $35 \%$ by episode and $3 \%$ by test). More than half of the participants (56\%) assigned accessions by episode and counted rejections by specimen. For this group, the average haemolysis rate per 100,000 episodes was 177 rejected specimens with the average rate varying from 100 to 233 over time. The majority of participants (91\%) determined rejections using the haemolysis index. Two thirds of participants $(66 \%)$ recorded the haemolysis manually in laboratory information systems.

Conclusions: KIMMS maintains the largest longitudinal haemolysis database in the world. However, as a means of advancing improvements in the quality of the preanalytical laboratory process, there is a need to standardise reporting methods to enable robust comparison of haemolysis rejection rates across participant laboratories.

Keywords: haemolysis; laboratory medicine; laboratory monitoring and management systems; patient safety; preanalytical errors; quality control; specimen rejection.

\section{Introduction}

Haemolysis refers to the breakdown of red blood cells (also known as erythrocytes) and the release of haemoglobin into the surrounding fluid [1]. Haemolysis is one of the most common causes of preanalytical errors, which can affect the integrity of a blood specimen and the reliability of laboratory results $[2,3]$. The presence of haemolysed specimens has major implications for the quality and safety of patient care $[4,5]$, constituting an area of major importance for laboratories in Australia and around the world [2]. Benchmark data about the prevalence and variation of haemolysis across laboratories can make a valuable contribution to the development of safe practises to reduce haemolysis and potential errors in laboratory results. Reduction in haemolysis rates can enhance the effectiveness of laboratory services and their contribution to safe and quality patient care.

Benchmark data at local, regional and national level have not been widely available. In 2009, 156 European laboratories participated in a survey about practises for 
identifying and rejecting haemolysed specimens [6]. The survey was launched under the auspices of the European Scientific Advisory Board (now Global Preanalytical Scientific Committee) [7]. In the United States, 772 laboratories reported their haemolysis identification and rejection practises to a similar survey conducted by Howanitz et al. [8]. Both surveys found that haemolysis practises varied widely, and about $70 \%$ of laboratories reported a haemolysis rate below $2.9 \%$. However, these surveys provided information only at a single point in time and did not track changes over time.

The key incident monitoring and management systems (KIMMS) project in Australia has established an ongoing patient safety project to monitor laboratory incidents, including haemolysis. The project was originally developed by the Royal College of Pathologists of Australasia and was made available through the Royal College of Pathologists of Australasia Quality Assurance Programs (RCPAQAP) and funded by the Australian Department of Health via a Quality Use of Pathology Program (QUPP) grant. Laboratories from across all Australian States and Territories submit data on a quarterly basis to a centralised repository to establish a benchmark of incidents and monitor data for a variety of different types of preanalytical errors (e.g. patient misidentification, incorrect specimen labelling, haemolysed specimens and other specimen problems) and postanalytical errors (e.g. results going to an incorrect destination or recipient and amendment or retraction of laboratory results already issued). Although the programme is open to laboratories overseas, at this stage there are only Australian-based participants.

The KIMMS database provides an opportunity to investigate existing laboratory practises for identifying and reporting haemolysis and to establish benchmark data over time. One of the barriers preventing the aggregation of benchmark data is the wide variation of criteria for the identification and rejection of haemolysed specimens currently used by laboratories in KIMMS. The aims of this study were thus (1) to assess suitability of KIMMS for quality monitoring of haemolysis across laboratories and (2) to devise a standardised reporting and analysis method to examine the prevalence and variations in practise of haemolysis rejection.

\section{Materials and methods}

\section{Study design and participants}

This was a retrospective cohort study utilising the haemolysis data collected in the KIMMS database from 2011 to 2014. In the KIMMS database, the term "participants" can refer to either a single physical laboratory or a group of affiliated laboratories at one or more physical locations. Each participant enroled and submitted aggregated quarterly reports of all individual laboratories within the participant organisation to the KIMMS database.

\section{Haemolysis}

The KIMMS database recorded instances when any specimens where one or more tests were not performed or one or more results were rejected or not reported due to haemolysis. It should be noted that not all haemolysed specimens are necessarily rejected. Participants considered many factors when deciding whether or not to reject a specimen, including the types of tests that were requested on a specimen and the test assay's sensitivity to haemolysis. Terminology used in the KIMMS database, such as accession, is defined in Table 1.

\section{Structured survey}

There were a variety of methods that laboratory participants used for accessioning and for counting haemolysis rejections. Participants variously assign accessions by episode, where multiple specimens and tests to be conducted for a single patient were all grouped into a single accession number, or by specimen, where each specimen was assigned its own accession number (even if it belonged to the same episode as other specimens with different accession numbers). Similarly, participants variously counted haemolysis rejections according to the number of episodes affected by haemolysis, according to the number of specimens affected by haemolysis, or according to the number of tests affected by haemolysis.

Because of this variety in the way different laboratories record their data, not all this information was consistently captured in KIMMS. We devised and conducted a structured survey (see Table 2) to clarify these parameters and gain an understanding of how laboratories captured their data in practise. The survey asked participants to describe: (a) the source of the majority of specimens arriving at their laboratories and whether most specimens were collected by laboratory phlebotomists or clinical staff, (b) the definition used for assigning accessions, (c) what method was used to detect haemolysed specimens, (d) whether haemolysis rejections were identified in the specimen reception area (SRA) or within each laboratory department, (e) how these rejections were recorded in laboratory information systems (LIS) and (f) how rejections were defined for the numerical counts submitted to KIMMS.

\section{Data and data linkage}

Data were extracted from the KIMMS database across 16 quarterly data reports covering a total period of four calendar years (20112014). The survey data were linked with the KIMMS quarterly data by de-identified laboratory participant numbers. Ethical approval was obtained from the UNSW Australia and the Macquarie University Human Research Ethics Advisory Panels (9_13_037). 
Table 1: Definitions of terms used in the KIMMS database.

\begin{tabular}{ll}
\hline Term & Definition \\
\hline Test & $\begin{array}{l}\text { An individual laboratory assay request to be processed by the laboratory } \\
\text { Specimen }\end{array}$ \\
& $\begin{array}{l}\text { Broadly defined as a container of tissue for which one or more tests have been requested. Examples of tissue are blood, urine, } \\
\text { faeces, pus, and other body fluids and solid tissue. Containers with specific preservatives would normally be regarded as } \\
\text { different specimens from the same episode } \\
\text { However, in this article, as we are dealing with haemolysis of blood samples, we generally use the term to mean a blood } \\
\text { specimen, unless otherwise specified }\end{array}$ \\
A collection of one or more tests, to be conducted on one or more specimens, that constitute a single request (order) for a \\
single patient, generally taken at a single point in time \\
An accession is a laboratory identification number assigned by the laboratory to allow identification, tracking and reporting of \\
results in laboratory information systems [9] for one or more tests. Accessions can be typically assigned \\
(i) by episode \\
$\quad$ - which can include multiple individual blood specimens drawn at the same time or over a short period, or multiple tests \\
$\quad$ run for the same patient; \\
$\quad$ - by laboratory department, \\
(ii) $\quad$ or by specimen \\
$\quad$ - multiple individual specimens can be taken at once, but in this case they are each assigned different tracking numbers; \\
- and this may vary between laboratories and organisations
\end{tabular}

Table 2: KIMMS participant survey questions.

Participant number:

(1) How are KIMMS accessions assigned?

(a) per sample (b) per episode

(2) What Disciplines do you collect accessions from?

(3) Are these the same as those you collect KIMMS data from? Yes/No

(4) Approx. proportion of accessions for each discipline

(5) Has the KIMMS data been consistently counted since 2011? Yes/No

(6) What proportion of your accessions come from?
(a) public hospital
(b) private hospital

(c) GP/specialist/other

(7) What proportion of your accessions are collected by:

(a) your employees (b) other

Haemolysis rejections

(8) How do you count Haemolysis rejections?

(a) per tube (b) per test (c) per department (d) per episode

(9) Where do you decide the haemolysis rejections?

(a) specimen reception area (SRA) (b) destination laboratory department (c) mix

(10) How do you decide haemolysis rejections-haemolysis index (HI)? Yes/No

(11) Recorded in the LIS

a) automatically (b) manually (c) mix

\section{Statistical analysis method for reporting haemolysis}

When examining the characteristics and practises of participating organisations, we included all accessions in the analysis. However, occasionally, participant organisations failed to report haemolysis data within their overall KIMMS submission, so only those quarterly submissions with data submitted by a laboratory on its haemolysis reporting were included in the haemolysis-related analyses. The haemolysis rejection rate was calculated by dividing the number of haemolysis rejections by the number of accessions (variously defined, see earlier) reported by the participant for a given time period. It was not appropriate to calculate an overall haemolysis rejection rate for the entire KIMMS data set because participants assigned accessions and counted haemolysis rejections using a variety of definitions (as described above). The haemolysis rejection rates and their 95\% confidence intervals (CIs) were calculated for participants for each of the five different combinations of accessioning practises and methods for counting haemolysis. Data analyses were conducted using SAS software, Version 9.4 of the SAS System for Windows. Copyright (C) 2002-2012 SAS Institute Inc. SAS and all other SAS Institute Inc. product or service names are registered trademarks or trademarks of SAS Institute Inc., Cary, NC, USA.

\section{Results}

\section{KIMMS laboratory participants' characteristics}

A total of 1017 quarterly reports were submitted to KIMMS from 68 participants across Australia from 2011 to 2014. On average, 7,103,487 accessions per quarter were reported (a total of 113,655,796 accessions). The majority of participants $(n=57 ; 84 \%)$ reported accessions by episodes, the rest $(n=11 ; 16 \%)$ by specimens. Table 3 shows that the majority of participants $(n=51 ; 75 \%)$ received most of their specimens from inpatients in government public hospitals; this group accounted for more than one third of all accessions (37\%) and three participants who received an approximately equal number of accessions from inpatients in both public and private hospitals. Another group 
Table 3: Source of the majority of specimens.

\begin{tabular}{lrrrr}
\hline Specimens collected from & No. of participants & \% of participants & No. of accessions & \% of accessions \\
\hline Other (outpatient, referred patient, etc.) & 13 & 19 & $65,079,684$ & 57 \\
Hospital-public & 51 & 75 & $41,579,102$ & 37 \\
Hospital-public and private & 3 & 4 & $5,985,420$ & 1 \\
Hospital-private & 1 & 1 & $1,011,590$ & 100 \\
Total & 68 & 100 & $11,655,796$ & \\
\hline
\end{tabular}

Table 4: Staff type which collected the majority of specimens.

\begin{tabular}{lrrrr}
\hline Specimen collector & No. of participants & \% of participants & No. of accessions & \% of accessions \\
\hline Laboratory phlebotomist & 47 & 69 & $81,288,155$ & 72 \\
Both & 3 & 4 & $8,259,610$ & 7 \\
Clinical staff & 11 & 16 & $8,169,686$ & 7 \\
(Missing/unknown) & 7 & 10 & $15,938,345$ & 14 \\
Total & 68 & 100 & $113,655,796$ & 100 \\
\hline
\end{tabular}

of participants $(n=13 ; 19 \%)$ reported that most of their accessions came from other sources (outpatient, community patient, referred patient etc.). This group accounted for over half of all accessions in the KIMMS database (57\%). A total of 47 participants, accounting for $72 \%$ of all accessions, reported in the survey that laboratory phlebotomists did most of the specimen collections (Table 4).

\section{Haemolysis}

Almost all quarterly reports $(n=1002 ; 99 \%)$ included haemolysis rejection data (Table 5). A total of 230,845 haemolysis rejections were reported. Forty-two participants $(62 \%)$ counted their haemolysis rejections by specimen, 24 (33\%) by episode and two by test (3\%). Two thirds of participants recorded the haemolysis rejections by manually entering them into the laboratory information system (LIS) $(n=45 ; 66 \%)$, and only one quarter were automatically recorded by the analysing equipment that interfaced with the LIS ( $n=18 ; 26 \%)$, and three participants $(4 \%)$ reported using both recording methods.

\section{Haemolysis detection location and methods}

Out of 68 participants, the majority $(n=62 ; 91 \%)$ reported that the haemolysis detection process occurred when the specimen arrived in the destination laboratory department; five other participants (7\%) reported that the haemolysis detection process occurred in the SRA or the destination laboratory departments and the one remaining participating organisation did not report where the detection occurred.

Similarly, 62 participants (91\%) decided rejection using the haemolysis index (HI) and five other participants $(7 \%)$ made these decisions without the index, i.e. visual inspection, including the use of a colour chart. The one remaining participating organisation did not report how they made these decisions.

Table 5: Haemolysis rejections by reporting groups.

\begin{tabular}{|c|c|c|c|c|c|c|c|}
\hline $\begin{array}{l}\text { Accession } \\
\text { assigned by }\end{array}$ & $\begin{array}{l}\text { Haemolysis } \\
\text { counted by }\end{array}$ & $\begin{array}{r}\text { No. of } \\
\text { participants }\end{array}$ & $\begin{array}{r}\text { No. of } \\
\text { quarterly } \\
\text { submissions }\end{array}$ & $\begin{array}{r}\text { No. of } \\
\text { haemolysis } \\
\text { rejections }\end{array}$ & $\begin{array}{r}\text { No. of } \\
\text { accessions }\end{array}$ & $\begin{array}{r}\text { Rate, number of } \\
\text { rejections per } 100,000 \\
\text { accessions }(95 \% \mathrm{Cl})\end{array}$ & $\begin{array}{r}\text { Percentage of } \\
\text { haemolysis rejections } \\
\text { of all accessions }\end{array}$ \\
\hline \multirow[t]{2}{*}{ Per specimen } & Per specimen & 4 & 27 & 15,190 & $18,505,638$ & $83(81-84)$ & $0.08 \%$ \\
\hline & Per episode & 7 & 110 & 69,052 & $5,300,854$ & $1303(1293-1313)$ & $1.30 \%$ \\
\hline \multirow[t]{3}{*}{ Per episode } & Per specimen & 38 & 579 & 70,605 & $39,997,983$ & $177(176-178)$ & $0.18 \%$ \\
\hline & Per test & 2 & 32 & 3,466 & $22,147,372$ & $16(15-17)$ & $0.02 \%$ \\
\hline & Per episode & 17 & 254 & 72,532 & $26,928,824$ & $270(268-272)$ & $0.27 \%$ \\
\hline Total & & 68 & 1002 & 230,845 & $112,880,671$ & & \\
\hline
\end{tabular}




\section{Prevalence and variation of specimens rejected due to haemolysis}

Given different methods were used for accessioning and for counting haemolysis rejections, the haemolysis rejection rates were reported separately (see Table 5) for the five groups using different combinations of accessioning practises and methods for counting haemolysis. The largest group of participant organisations $(n=38)$ with the most accessions reported ( $\sim 40$ million) who defined accessions assigned by episode and haemolysis rejections counted by specimen reported a mean haemolysis rejection rate of 177 rejections per 100,000 accessions. The second largest group of participant organisations (17 organisations with $\sim 27$ million accessions, accessions assigned by episode, haemolysis rejections counted by episode) reported a mean haemolysis rejection rate of 270 rejections per 100,000 accessions.

To examine the haemolysis rejection rates over time, we focused the subsequent analysis on the 38 participant organisations who used the most common method of accessioning and counting haemolysis rejections, i.e. accessions assigned by episode, haemolysis rejections counted by specimen. Haemolysis specimen rejections per 100,000 episodes for each quarter and year of the study period are presented in Figure 1. The quarterly haemolysis rejection rate between 2011 and 2014 fluctuated between 100 and 233 rejections per 100,000 accessions.
The variations of haemolysis rejection rates between 38 participant organisations were very similar over time as shown in the 95\% CIs in Figure 1.

\section{Discussion}

To our knowledge, KIMMS maintains the largest existing longitudinal haemolysis data set in the world. The results of this study revealed considerable variation between participants with respect to where the majority of accessions came from, which type of staff performed the actual specimen collections, what method was used for haemolysis detection, where it occurred in the laboratory process and how rejections for haemolysis were counted. Broadly speaking, the prototypical KIMMS participant organisations received most of the specimens from inpatients in public hospitals, received a majority of specimens that had been collected by phlebotomists, identified haemolysed specimens within each laboratory department using the HI result generated by a chemistry analyser, assigned accessions according to the episode, counted haemolysis rejections per specimen and recorded this information manually in LIS.

This study also identified areas that could improve the quality of future reporting and monitoring of haemolysis rejections. First, the most important conclusion

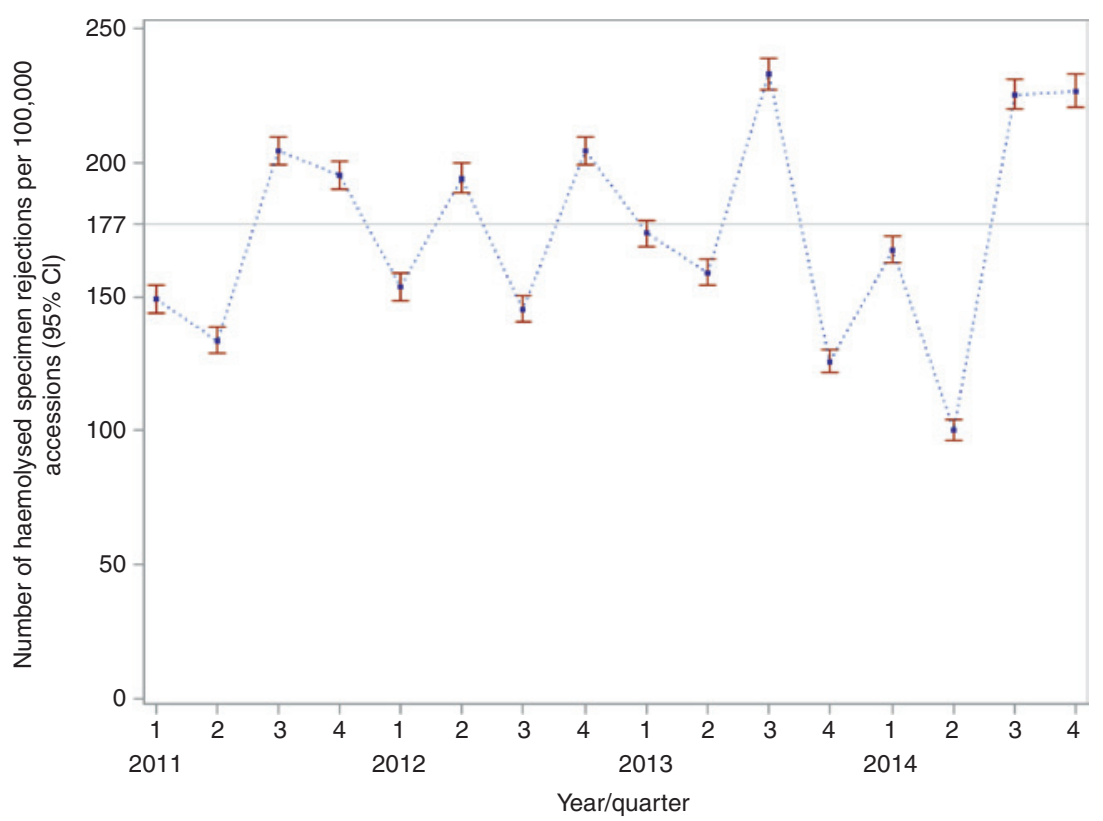

Figure 1: Numbers of haemolysis specimen rejections per 100,000 episode accessions from the first quarter (Q1) of 2011 to the fourth quarter (Q4) of 2014 for the 38 KIMMS participants who assigned accessions per episode and counted haemolysis rejections per specimen (overall mean $=177$ specimen rejections per 100,000 episode accessions as shown by the horizontal line, i.e. $0.18 \%$ of all accessions). 
is that there is a need to standardise reporting methods among the KIMMS participants. Of 68 participating organisations, a variety of methods were used for accessioning and counting haemolysis rejections, this systematically influenced the haemolysis rejection rates and made it inappropriate to compare haemolysis rejection rates between laboratory participants that had used different methods. Without standardisation of these recording metrics, deriving useful comparisons, benchmarks and targets will not be possible. Participants varied both in how they assigned accessions (whether it was according to the specimen or to the episode, definitions see Table 1) and how they counted haemolysis rejections for submission to the KIMMS database (by episode, by specimen or by test). Episodes can contain multiple specimens upon each of which multiple tests might be requested. Because the haemolysis rejection rate was calculated by dividing the number of haemolysis rejections by the number of accessions processed by the participant for a given period, differences in how these were defined systematically altered the resultant rates. Participants who counted haemolysis rejections per test recorded a lower rate of haemolysis rejections (16 rejections per 100,000 accessions for two participants) compared with other participants, but this low rate is probably an artefact of how they capture and report their data.

Second, KIMMS participant laboratories did not report haemolysis detection methods and their operational haemolysis cutoff parameters, including the criteria used for haemolysis rejections. Nor did they report the assay methodology and/or the instrumentation that was used, which may determine the point at which haemolysis interferes with the accuracy of a result. These factors would have influenced the rate of haemolysis rejection reported.

Third, we identified a need for the KIMMS participants to report blood specimen accessions separately. Haemolysis mainly affects blood specimens, while participants contributing data to the KIMMS database reported their activity by the number of accessions for all types of specimens (including tissue specimens, and faeces, etc., for which haemolysis was not necessarily relevant). Although the majority of the specimens collected in the laboratories were blood specimens and haemolysis is one of the most common causes of preanalytical errors $[2,3]$, laboratories' haemolysis rates would be systematically affected by the proportion of their activity that was performed on other than blood specimens. When the haemolysis rate is calculated using the total number of accessions (regardless of specimen type), laboratories whose activity was dominated by tests on blood specimens would report artificially higher rates of haemolysis than laboratories that did a smaller proportion of tests on blood specimens.

Fourth, providing regular feedbacks to laboratory participants will help them to track their performance over time, to enable comparison and benchmarking with their peers. We devised a reporting and analysis method to examine the haemolysis rates for participants. Based on participants' reporting methods, five haemolysis rejection rates were calculated by dividing the number of haemolysis rejections by the number of accessions.

Lastly, we identified the lack of information about KIMMS participants and their haemolysis detection and reporting practises. We conducted a survey to retrospectively collect the missing information (Table 2). This information should be reported when participants begin to report to KIMMS and then regularly updated (e.g. on a quarterly basis). The findings from this study highlight the need for newer data collection methods for haemolysis identification reporting, which take advantage of the widespread use of electronic LIS in laboratory services. We found that two thirds of KIMMS participants recorded the haemolysis rejections manually in their LIS. A 2014 survey of Australian biochemistry laboratories reported that $97 \%$ of respondents were using an electronic LIS [10]. Using routinely and automatically collected and recorded data from the LIS reduces the likelihood of errors in the data submitted [11, 12] and facilitates the process of sharing data with the KIMMS database, potentially allowing for more frequent update intervals and a faster feedback loop. Various electronic laboratory systems, while undoubtedly useful, are yet to embrace all of their potential because of problems with the interoperability between systems and the aggregation of data [13, 14]. Aggregating data across these multiple systems, and from laboratories employing different criteria and definitions, would greatly facilitate the monitoring of laboratory quality performance and provide a valuable means to generate research evidence.

Despite the limitations of KIMMS data, the overall haemolysis rates, ranging from $0.02 \%$ to $1.3 \%$ depending on the ways of reporting (Table 5), concur with other literature. Based on the data from the International Federation of Clinical Chemistry and Laboratory Medicine (IFCC), the median haemolysis rates varied from $0.270 \%$ to $0.850 \%$ during the period of 2009-2013 [15]. A literature review located 37 studies published between 2000 and 2014, which reported an overall rate of haemolysis and methods used to detect haemolysis (HI and/or visual inspection) [16]. A considerable variation in haemolysis rates reported in the literature was identified. Seven 
studies reported a haemolysis rejection below $1 \%$ of all accessions [17-23], six between 1\% and 3\% [24-29], 20 between 3\% and 20\% [9, 30-48] and another four above 20\% [49-52]. Haemolysis detection methods, and free plasma haemoglobin levels used for this detection, are likely to be partly responsible for this variation, in addition to the differences in study designs and study populations. Although further research is called for to understand these factors related to variation of haemolysis rates, future studies should aim to generate benchmark data of haemolysis rates with consideration of the haemolysis detection methods used.

As noted above, the wide range of practises in use for recording both accessions/specimens and haemolysis will confound the development of useful benchmarks and standards for good laboratory practise. As a consequence of this study, a guideline on managing and reporting of haemolysed specimens [53] has already been developed by the Australian Association of Clinical Biochemists and KIMMS custodian, the Royal College of Pathologists of Australasia, and was made available through the RCPAQAP. It is anticipated that this guideline will find its way into routine pathology practise across Australia, and through this, the ability to set appropriate standards for haemolysis, and for laboratories to be able to measure their performance against these standards, will become possible.

This study provided a foundation for further thorough investigation of all other quality indicators, i.e. pre- and postanalytical errors, recorded in KIMMS. Haemolysis is one of 21 quality indicators recorded in KIMMS. The research methods used in this study can be applied to assess other KIMMS quality indicators and potentially generate other benchmark data. Standardisation of haemolysis detection and reporting criteria would make it possible to compare KIMMS data with the other established international data, such as the data from the IFCC $[54,55]$. Similarly, standardised detection and reporting facilitate laboratories by tracking their performance and improving the safety and efficiency of laboratory processes and, consequently, patient care through targeted interventions to reduce errors.

\section{Limitation}

The recall bias could affect the survey results because the information about KIMMS participants and haemolysis detection and reporting were not recorded in KIMMS. However, this information does not change frequently according to the custodians of KIMMS.

\section{Conclusions}

The KIMMS project has established a unique repository to benchmark incidence and monitoring data over time for a variety of different types of pre- and postanalytical errors, including haemolysis. However, there is a need to standardise reporting methods to enable comparisons of haemolysis rejection rates between different laboratories. Since haemolysis can affect the integrity of the specimen and the reliability of laboratory results, standardised reporting of the occurrence of haemolysis may support the improvement of the quality and efficiency of the preanalytical laboratory process.

Author contributions: LL and SG devised the participant survey; SG conducted the survey; LL conducted analyses; and LL, EV and RL drafted the manuscript. All authors contributed to the study design, reviewed the manuscript and approved the final manuscript submission.

Research funding: This project was funded by the Royal College of Pathologists Australasia Quality Assurance Programs (RCPAQAP) and an Australian Government Department of Health: Quality Use of Pathology Program (QUPP) grant.

Employment or leadership: None declared.

Honorarium: None declared.

Competing interests: The funding organization(s) played no role in the study design; in the collection, analysis, and interpretation of data; in the writing of the report; or in the decision to submit the report for publication.

\section{References}

1. Franco R. The measurement and importance of red cell survival. Am J Hematol 2009;84:109-14.

2. Lippi G, Blanckaert N, Bonini P, Green S, Kitchen S, Palicka V, et al. Haemolysis: an overview of the leading cause of unsuitable specimens in clinical laboratories. Clin Chem Lab Med 2008;46:764-72.

3. Simundic AM, Topic E, Nikolac N, Lippi G. Hemolysis detection and management of hemolyzed specimens. Biochem Med 2010;20:154-9.

4. Bonini P, Plebani M, Ceriotti F, Rubboli F. Errors in laboratory medicine. Clin Chem 2002;48:691-8.

5. Lippi G, Guidi G, Mattiuzzi C, Plebani M. Preanalytical variability: the dark side of the moon in laboratory testing. Clin Chem Lab Med 2006;44:358-65.

6. Lippi G. Practices for identifying and rejecting hemolyzed specimens in Europe. Arch Pathol Lab Med 2016;140:622.

7. Specimencare.com. Global Preanalytical Scientific Committee. Available at: http://www.specimencare.com. Accessed: 24 Mar 2017. 
8. Howanitz P, Lehman C, Jones B, Meier F, Horowitz G. Practices for identifying and rejecting hemolyzed specimens are highly variable in clinical laboratories. Arch Pathol Lab Med 2015;139:1014-9.

9. Dugan L, Leech L, Speroni KG, Corriher J. Factors affecting hemolysis rates in blood samples drawn from newly placed IV sites in the emergency department. J Emerg Nurs 2005;31:338-45.

10. Streitberg G, Angel L, Sikaris K. Laboratory information systems in clinical biochemistry in Australia. Aust J Med Sci 2014;35:2-8.

11. Fifield $L$. The need for usability in electronic lab ordering. MLO Med Lab Obs 2013;45:14.

12. Georgiou A, Vecellio E, Toouli G, Eigenstetter A, Li L, Wilson R, et al. Monitoring the impact of the electronic medical record on the quality of laboratory test ordering practices. In: Grain H, Schaper LK, editors. Health informatics: digital health service delivery - the future is now! 1st ed. Amsterdam: IOS Press, 2013:33-8.

13. Park S, Pantanowitz L, Parwani A. Quality assurance in anatomic pathology. Diagn Histopathol 2013;19:438-46.

14. Sepulveda J, Young D. The ideal laboratory information system. Arch Pathol Lab Med 2013;137:1129-40.

15. Plebani M, Sciacovelli L, Aita A, Pelloso M, Chiozza ML. Performance criteria and quality indicators for the pre-analytical phase. Clin Chem Lab Med 2015;53:943-8.

16. McCaughey E, Vecellio E, Lake R, Li L, Gay S, Mackay M, et al. Current methods of haemolysis detection and reporting as a source of risk to patient safety: a narrative review. Clin Biochem Rev 2016;37:143-51.

17. Atay A, Demir L, Cuhadar S, Saglam G, Unal H, Aksun S, et al. Clinical biochemistry laboratory rejection rates due to various types of preanalytical errors. Biochem Med 2014;24:376-82.

18. Carraro P, Zago T, Plebani M. Exploring the initial steps of the testing process: frequency and nature of pre-preanalytic errors. Clin Chem 2012;58:638-42.

19. Chawla R, Goswami B, Tayal D, Mallika V. Identification of the types of preanalytical errors in the clinical chemistry laboratory: 1-year study at G.B. Pant Hospital. Lab Med 2010;41:89-92.

20. Dietrich H. One poke or two: can intravenous catheters provide an acceptable blood sample? A data set presentation, review of previous data sets, and discussion. J Emerg Nurs 2014;40:575-8.

21. Goswami B, Singh B, Chawla R, Mallika V. Evalutation of errors in a clinical laboratory: a one-year experience. Clin Chem Lab Med 2010;48:63-6.

22. Grecu DS, Vlad DC, Dumitrascu V. Quality indicators in the preanalytical phase of testing in a stat laboratory. Lab Med 2014;45:74-81.

23. Lippi G, Bassi A, Brocco G, Montagnana M, Salvagno GL, Guidi GC. Preanalytic error tracking in a laboratory medicine department: results of a 1-year experience. Clin Chem 2006;52:1442-3.

24. Berger-Achituv S, Budde-Schwartzman B, Ellis MH, Shenkman Z, Erez I. Blood sampling through peripheral venous catheters is reliable for selected basic analytes in children. Pediatrics 2010;126:e179-86.

25. Carraro P, Servidio G, Plebani M. Hemolyzed specimens: a reason for rejection or a clinical challenge? Clin Chem 2000;46:306-7.

26. Cox SR, Dages JH, Jarjoura D, Hazelett S. Blood samples drawn from IV catheters have less hemolysis when 5-mL (vs. 10-mL) collection tubes are used. J Emerg Nurs 2004;30:529-33.
27. Fernandez P, Llopis MA, Perich C, Alsina MJ, Alvarez V, Biosca C, et al. Harmonization in hemolysis detection and prevention. $\mathrm{A}$ working group of the Catalonian Health Institute (ICS) experience. Clin Chem Lab Med 2014;52:1557-68.

28. Romero A, Cobos A, López-León A, Ortega G, Muñoz M. Preanalytical mistakes in samples from primary care patients. Clin Chem Lab Med 2009;47:1549-52.

29. Salvagno GL, Lippi G, Bassi A, Poli G, Guidi GC. Prevalence and type of pre-analytical problems for inpatients samples in coagulation laboratory. J Eval Clin Pract 2008;14:351-3.

30. Berg JE, Ahee P, Berg JD. Variation in phlebotomy techniques in emergency medicine and the incidence of haemolysed samples. Ann Clin Biochem 2011;48:562-5.

31. Bölenius K, Söderberg J, Hultdin J, Lindkvist M, Brulin C, Grankvist K. Minor improvement of venous blood specimen collection practices in primary health care after a large-scale educational intervention. Clin Chem Lab Med 2013;51:303-10.

32. Brunel V, Larson T, Peschanski N, Cauliez B. Evaluation of haemolysis in emergency department samples requesting high sensitivity troponin T measurement. Ann Clin Biochem 2012;49:509-10.

33. Burns ER, Yoshikawa N. Hemolysis in serum samples drawn by emergency department personnel versus laboratory phlebotomists. Lab Med 2002;33:378-80.

34. Davidson DF. A survey of some pre-analytical errors identified from the biochemistry department of a Scottish hospital. Scot Med J 2014;59:91-4.

35. Dwyer DG, Fry M, Somerville A, Holdgate A. Randomized, single blinded control trial comparing haemolysis rate between two cannula aspiration techniques. Emerg Med Australas 2006;18:484-8.

36. Ellis G. An episode of increased hemolysis due to a defective pneumatic air tube delivery system. Clin Biochem 2009;42:1265-9.

37. Fang L, Fang S-H, Chung Y-H, Chien S-T. Collecting factors related to the haemolysis of blood specimens. J Clin Nurs 2008;17:2343-51.

38. Giménez-Marin A, Rivas-Ruiz F, del Mar Pérez-Hidalgo M, Molina-Mendoza P. Pre-analytical errors management in the clinical laboratory: a five-year study. Biochem Med 2014;24:248-57.

39. Kara H, Bayir A, Ak A, Degirmenci S, Akinci M, Agacayak A, et al. Hemolysis associated with pneumatic tube system transport for blood samples. Pak J Med Sci 2014;30:50-8.

40. Lowe G, Stike R, Pollack M, Bosley J, O'Brien P, Hake A, et al. Nursing blood specimen collection techniques and hemolysis rates in an emergency department: analysis of venipuncture versus intravenous catheter collection techniques. J Emerg Nurs 2008;34:26-32.

41. Munnix IC, Schellart M, Gorissen C, Kleinveld HA. Factors reducing hemolysis rates in blood samples from the emergency department. Clin Chem Lab Med 2010;49:157-8.

42. Saleem S, Mani V, Chadwick MA, Creanor S, Ayling RM. A prospective study of causes of haemolysis during venepuncture: tourniquet time should be kept to a minimum. Ann Clin Biochem 2009;46:244-6.

43. Söderberg J, Jonsson PA, Wallin O, Grankvist K, Hultdin J. Haemolysis index - an estimate of preanalytical quality in primary health care. Clin Chem Lab Med 2009;47:940-4.

44. Sodi R, Darn SM, Davison AS, Stott A, Shenkin A. Mechanism of interference by haemolysis in the cardiac troponin T immunoassay. Ann Clin Biochem 2006;43:49-56. 
45. Straszewski SM, Sanchez L, McGillicuddy D, Boyd K, DuFresne J, Joyce N, et al. Use of separate venipunctures for IV access and laboratory studies decreases hemolysis rates. Intern Emerg Med 2011;6:357-9.

46. Tanabe P, Kyriacou DN, Garland F. Factors affecting the risk of blood bank specimen hemolysis. Acad Emerg Med 2003;10:897-900.

47. Wollowitz A, Bijur PE, Esses D, Gallagher EJ. Use of butterfly needles to draw blood is independently associated with marked reduction in hemolysis compared to intravenous catheter. Acad Emerg Med 2013;20:1151-5.

48. Lippi G, Bonelli P, Cervellin G. Prevalence and cost of hemolyzed samples in a large urban emergency department. Int J Lab Hematol 2014;36:e24-6.

49. Grant MS. The effect of blood drawing techniques and equipment on the hemolysis of ED laboratory blood samples. J Emerg Nurs 2003;29:116-21.

50. Lippi G, Avanzini P, Aloe R, Cervellin G. Blood collection from intravenous lines: is one drawing site better than others? Lab Med 2014;45:172-5.
51. Shah KG, Idrovo JP, Nicastro J, McMullen HF, Molmenti EP, Coppa $\mathrm{G}$. A retrospective analysis of the incidence of hemolysis in type and screen specimens from trauma patients. Int Angiol 2009;18:182-3.

52. Stauss M, Sherman B, Pugh L, Parone D, Looby-Rodriguez K, Bell $A$, et al. Hemolysis of coagulation specimens: a comparative study of intravenous draw methods. J Emerg Nurs 2012;38:15-21.

53. Badrick T, Barden H, Callen S, Dimeski G, Gay S, Graham $P$, et al. Consensus statement for the management and reporting of haemolysed specimens. Clin Biochem Rev 2016;37:140-2.

54. Plebani M, Sciacovelli L, Aita A. Quality indicators for the total testing process. Clin Lab Med 2017;37:187-205.

55. Sciacovelli L, Lippi G, Sumarac Z, West J, Garcia Del Pino Castro I, Furtado Vieira K, et al. Quality indicators in laboratory medicine: the status of the progress of IFCC Working Group "Laboratory Errors and Patient Safety” project. Clin Chem Lab Med 2017;55:348-57. 